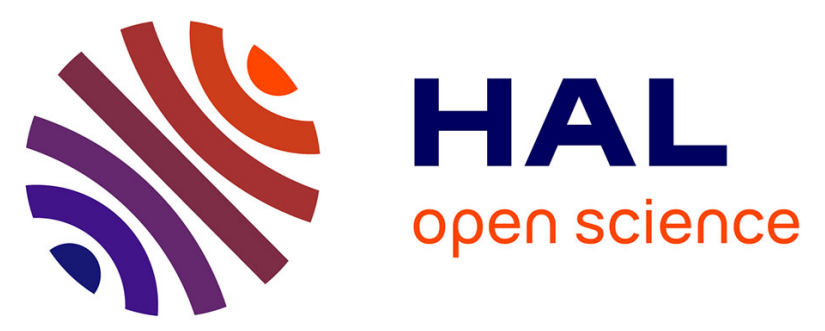

\title{
Effects of the powder, laser parameters and surface conditions on the molten pool formation in the selective laser melting of IN718
}

\author{
Yuze Li, Miha Založnik, Julien Zollinger, Lucas Dembinski, Alexandre \\ Mathieu
}

\section{To cite this version:}

Yuze Li, Miha Založnik, Julien Zollinger, Lucas Dembinski, Alexandre Mathieu. Effects of the powder, laser parameters and surface conditions on the molten pool formation in the selective laser melting of IN718. Journal of Materials Processing Technology, 2021, 289, pp.116930. 10.1016/j.jmatprotec.2020.116930 . hal-02978802

\section{HAL Id: hal-02978802 https://hal.science/hal-02978802}

Submitted on 23 Dec 2020

HAL is a multi-disciplinary open access archive for the deposit and dissemination of scientific research documents, whether they are published or not. The documents may come from teaching and research institutions in France or abroad, or from public or private research centers.
L'archive ouverte pluridisciplinaire HAL, est destinée au dépôt et à la diffusion de documents scientifiques de niveau recherche, publiés ou non, émanant des établissements d'enseignement et de recherche français ou étrangers, des laboratoires publics ou privés. 


\title{
Effects of the powder, laser parameters, and surface conditions on the molten pool formation in the selective laser melting of IN718
}

\author{
Yuze Li1 ${ }^{1,2}$, Miha Založnik ${ }^{1}$, Julien Zollinger ${ }^{1,}{ }^{*}$, Lucas Dembinski ${ }^{3}$, Alexandre Mathieu ${ }^{4}$ \\ ${ }^{1}$ Université de Lorraine, CNRS, IJL, F-54000 Nancy, France \\ ${ }^{2}$ IRT M2P, F-57078 Metz, France \\ ${ }^{3}$ LERMPS, ICB, CNRS, Univ. Bourgogne Franche-Comté, F-90010 Belfort, France \\ ${ }^{4}$ Laboratoire Interdisciplinaire Carnot de Bourgogne, UMR 6303 CNRS, Univ. Bourgogne \\ Franche-Comté, F-71200 Le Creusot, France
}

\begin{abstract}
A series of single-track selective laser melting (SLM) experiments was carried out on IN718 plates with and without a powder layer and with different laser processing parameters (power and scan velocity) and surface conditions (original surface and sand blasted surface). The impacts of the powder, laser parameters, and surface conditions on the molten pool (MP) formation in SLM were systematically investigated through characterizations of the geometry of the resolidified MP, including width, depth, and area. Clear-cut correlations between the dimensions of the MP and the parameters were deduced from the measured data, such as between width/depth of the MP and the power of the laser beam, or between the area of the MP and the laser energy density. We also show that without a powder layer, an increased roughness of the surface consistently increases the MP cross-section area, whereas it has no impact for the cases with powder layer. Finally, the occurrence of defects, such as insufficient melting, unstable MP, and porosities/keyhole effect, is investigated and linked to the SLM parameters. We propose a processing map that defines the range of laser velocity and power for a defectfree solidification of the MP and the occurrence of the different types of defects.
\end{abstract}

\section{Keywords:}

Powder Bed Fusion

Selective laser melting

Nickel based superalloy

Molten pool formation

Processing parameters 


\section{Introduction}

Additive manufacturing (AM) is a major breakthrough for the manufacturing industry, as reported by Moges et al. (2019). In AM processes, material is deposited layer by layer to produce parts. With this characteristic, AM attracts attention for the production of complex shaped parts in aerospace, automotive, and biomedical implant applications, as mentioned by Kenel et al. (2017) and Murr et al. (2013). As a powder bed laser melting process, selective laser melting (SLM) is a commonly used additive manufacturing technique and is often considered to be the most promising one. Bandyopadhyay and Traxel (2018) and Gokuldoss et al. (2017) pointed out its distinctive advantages compared to other AM processes: (1) a lower heat input in SLM induces lower distortions, which allows a higher dimensional precision for the final part; (2) the SLM process is suitable for many materials, especially for engineering metal alloys; (3) SLM can be conducted at a much higher speed with lower financial and material cost. Based on these advantages, Li et al. (2017) reported that the rapid manufacturing of geometrically complex near net shaped components can be achieved by the SLM process with good surface integrity. This is particularly interesting for superalloys such as IN718. As mentioned by Sadowski et al. (2016), the low thermal conductivity and high hardness of these alloys make them quite difficult to fabricate using conventional machining methods.

Saedi et al. (2018) reported that the SLM process generally consists of the formation of the molten pool (MP) by melting the powder in the laser path region and the MP solidification subsequently after the laser passes. Both experimental and modeling methods are used to investigate the SLM and other AM processes in many aspects. For instance, Chen et al. (2018) investigated heat and mass transfer phenomena in the MP, while Acharya et al. (2017) focused on the evolution of the microstructure in AM. Amato et al. (2012) studied the properties of the final product, and Khairallah et al. (2016) studied the formation of the defects in AM. Since the quality of the final part will be significantly impacted by the process parameters, the effect of 
the SLM parameters on the properties of the final part was also investigated by Liverani et al. (2017), who mainly focused on the power and the traveling velocity of the laser.

The MP formation is the elementary and primary step in the AM process. The structure of the solidified MP is the elementary building block of the AM processed part. The characterization and the understanding of MP formation under different AM conditions is therefore crucial for a well-founded understanding of the AM process, of the structure of AM processed parts, and of various defects. The traditional approach for investigating the effects of various parameters of the AM process is to use the final part consisting of many layers. Besides being highly time consuming and costly, the most important limitation of this technique is that the initial MP shape and the initial state of the solidified structure in the real AM process are concealed by the subsequent passes, which partially remelt the underlying layer. Therefore, single-track laser melting experiments, basically originating from studies of other similar processes, such as laser welding, reported by Fabbro (2010) and Fotovvati et al. (2018), are used as a substitute in some investigations aimed at a better understanding of the MP formation. Similar trends of melt pool characteristics between single-track, single-layer remelting and multilayer deposition of IN718 by SLM were reported by Kumar et al. (2019). Dilip et al. (2017) reported good correlation between porosity defects in bulk parts and single track melt pool geometry at the same process parameters. This shows that single-track experiments are a useful experimental tool for the understanding of the impact on process parameters on the MP characteristics and for the generation of processing maps. Ghosh et al. (2018) used single-track experiments to investigate the MP dimensions and final solidified structures under multiple combinations of different powers and scan velocities of the laser on Inconel 625, but only on a finished surface with no powder layer. Scime and Beuth (2019) studied the variability of MP geometry across process space for IN718 with a single powder layer. They associated the MP morphology in the crosssection with the surface balling and keyholing porosity defects, however without providing 
information on the correlation between the process parameters and the MP characterization. Ding et al. (2019) investigated the correlation between the process parameters and the MP characterization of IN718 for the electron beam melting technique, also on a finished surface without powder layer. They reported transitions between semi-elliptical and conical MP geometry, but without recognizing the keyhole problem. Kusuma et al. (2016 and 2017) used single-track experiments to investigate the impact of the laser parameters on the MP geometry and surface morphology for commercially pure titanium and for Ti-6Al-4V. The results show that the MP shape and properties are significantly impacted by the laser parameters. In addition to these experimental investigations, numerical modeling studies of the MP formation and of the molten track were also performed. In most cases, many simplifying assumptions were necessary to reduce the computational cost or to enable the application of the models. For instance, the powder bed was often assumed as a homogeneous and continuous material layer (Zhang et al., 2018), or as a homogenized porous (partly solid, partly gaseous) layer (Heeling et al., 2017). Highly sophisticated simulations that represent individual powder particles, as done by Khairallah et al. (2016), Chen et al. (2020) and Qiu et al. (2015), on the other hand, are too costly for extensive studies that would provide relations between process parameters and MP formation for a wide range of parameters. To summarize, more detailed and systematic studies are still required on the MP formation in the AM/SLM process, more precisely on the effect of process parameters, as well as on the effect of the structure of the powder layer and of surface conditions. Additionally, more information is needed on the link between various process conditions and the MP shape and dimensions in order to guide the physical ingredients and phenomena to be included in process models. Besides, the generation of processing maps for the MP features will be crucial and helpful for the guidance of the parameter selection in the AM/SLM process.

In the present work, single-track laser melting experiments were performed under different 
processing conditions in a SLM machine on two IN718 plates. The process parameters that were controlled and varied included: (i) laser parameters (laser power, $P$, scan velocity, $V$ ) corresponding to a wide range of energy density $\left(10-700 \mathrm{~J} / \mathrm{mm}^{2}\right.$ ), (ii) surface finish and (iii) presence/absence of a powder layer. The cross sections of the laser tracks were then characterized with the aim to (i) evaluate the effect of process parameters on the MP formation; (ii) determine quantitative correlations between the MP geometry and the process parameters; and (iii) design a processing map that provides the MP features and defects as a function of the SLM process parameters.

\section{Experiments}

\subsection{Experimental setup and parameters}

Single-track selective-laser-melting (SLM) experiments were conducted using an SLM250 REALIZER (REALIZER GmbH, Germany) machine with an Nd-YAG fiber laser source (continuous wave with wavelength $\lambda=1.064 \mu \mathrm{m}$ ) on IN718, with 28 different laser power and scan velocity combinations. The experiments were performed on IN718 superalloy plate substrates and on IN718 powder, under an argon environment with a residual oxygen level below $0.5 \%$. As shown in Fig. 1a, two identical IN718 plates with dimensions of $155 \times 155 \times 5$ $\mathrm{mm}$ were used. One half of the surface of each plate was sand blasted (SB), while the other half remained the original finished surface $(\mathrm{O})$. Additionally, on one plate a single powder layer of around $40 \mu \mathrm{m}$ thickness was added before processing. The mean size of the powder was $40 \mu \mathrm{m}$. The powder was deposited before laser melting (with powder layer - WP), while on the other plate the laser melting lines were performed directly, without powder (no powder - NP), as shown in Fig.1b and Fig.1c, respectively. This results in four different surface configurations. They are summarized in Table 1 along with the corresponding processing parameters. As shown in Table 1, a total of 112 conditions with cross-combined parameters were performed and 
characterized in this work.

\section{(a)}
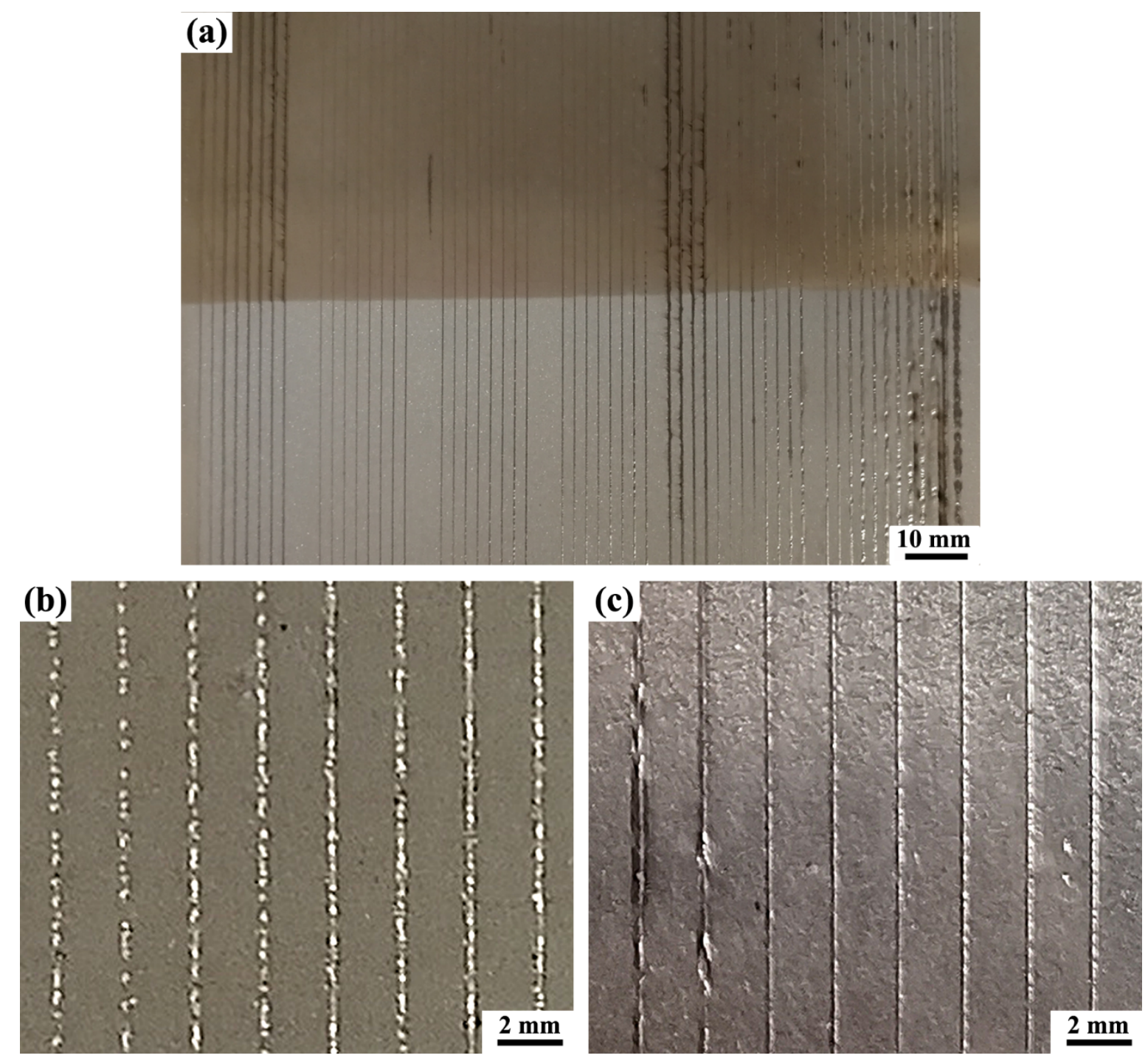

Fig.1. Surface view of the laser tracks for different parameters and surface conditions: (a) original surface (top half) and sand blasted surface (bottom half) without powder, (b) original surface without powder and (c) original surface with powder.

The laser spot size was stable at $D_{L}=35 \mu \mathrm{m}$ on the substrate surface. No pre-heating of the substrate was applied before SLM processing. The laser power, $P$, employed in this study ranged from $100 \mathrm{~W}$ to $250 \mathrm{~W}$, and the scanning velocity, $V$, ranged from $10 \mathrm{~mm} / \mathrm{s}$ to $600 \mathrm{~mm} / \mathrm{s}$, which was varied independently of the laser power. To standardize the correlation between the input energy and the MP geometry, the energy density of the laser, $E p\left(\mathrm{~J} / \mathrm{mm}^{2}\right)$, was also used, 
calculated with the equation reported by Kumar (2014) (see Table 1 for a summary):

$$
E p=\frac{P}{D_{L} V}
$$

where $P$ is the laser power, $D_{L}$ is the laser spot size, and $V$ is the laser scan velocity.

The naming convention for the individual cases is given in Table 1. For instance, the case NP_O_P100V50 refers to the sample processed directly on the substrate with no powder bed layer (NP), with the original surface (O), and with the parameter combination $P=100 \mathrm{~W}$ and $V=50 \mathrm{~mm} / \mathrm{s}$. Two melting tracks were performed for each case with the length of around $70 \mathrm{~mm}$ for each track. The distance between two tracks and different cases was larger than $2 \mathrm{~mm}$ to avoid thermal interaction of adjacent tracks. Both tracks were investigated to ensure reproducibility and stability of the processing conditions.

Table 1. Laser processing parameters and sample designation key.

\begin{tabular}{|c|c|c|c|c|c|c|}
\hline & \multirow{2}{*}{ Powder } & \multirow{2}{*}{$\begin{array}{l}\text { Surface } \\
\text { condition }\end{array}$} & \multicolumn{4}{|c|}{ Laser parameters } \\
\hline & & & $D_{L}, \mu \mathrm{m}$ & $P, \mathrm{~W}$ & $V, \mathrm{~mm} / \mathrm{s}$ & $E p, \mathrm{~J} / \mathrm{mm}^{2}$ \\
\hline \multirow{4}{*}{$\begin{array}{l}\text { Processing } \\
\text { parameters }\end{array}$} & \multirow{4}{*}{ NP/WP* } & \multirow{4}{*}{$\mathrm{O} / \mathrm{SB}^{*}$} & \multirow{4}{*}{35} & 100 & $30-200$ & $95.2-14.3$ \\
\hline & & & & 150 & $50-300$ & $85.7-14.3$ \\
\hline & & & & 200 & $50-500$ & $114.3-11.4$ \\
\hline & & & & 250 & $10-600$ & $714.3-11.9$ \\
\hline $\begin{array}{c}\text { Sample } \\
\text { designation }\end{array}$ & \multicolumn{6}{|c|}{ NP/WP_O/SB_PxxxVxxx } \\
\hline
\end{tabular}

* NP - No Powder, WP- With Powder,

$\mathrm{O}$ - Original surface, $\mathrm{SB}$ - Sand Blasted surface 


\subsection{Molten pool characterization}

After the SLM processing, the cross-sectional samples of all the melting tracks perpendicular to the laser scanning direction were prepared for metallographic analysis. The specimens were mechanically polished with abrasive SiC paper to 4000 \#. To clearly identify the MP boundary, the samples were then polished with a colloidal $50 \mathrm{~nm} \mathrm{SiO}_{2}$ suspension. Scanning electron microscopy (SEM) was used to characterize the prepared samples to ensure the precision of the MP geometry measurement.
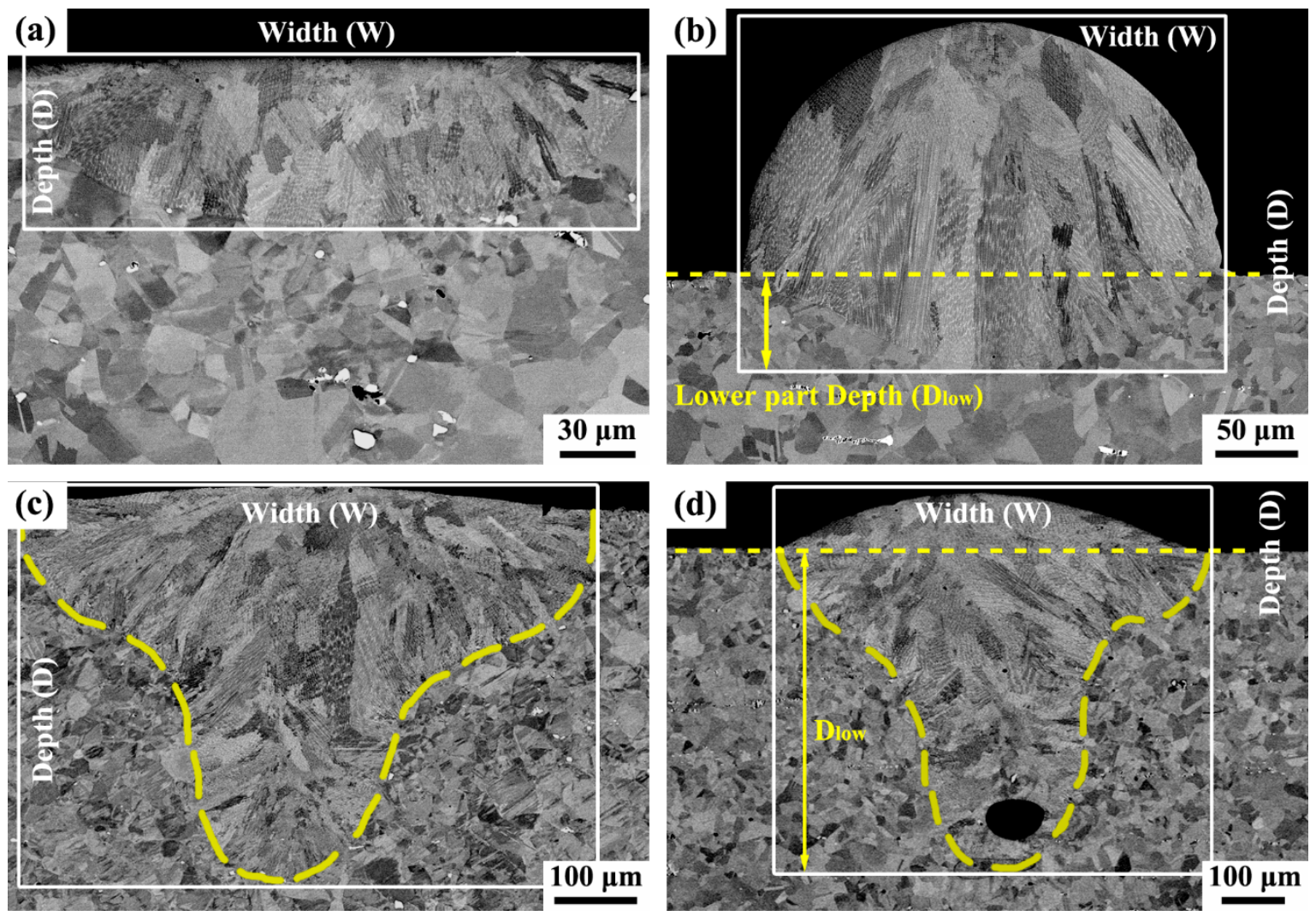

Fig.2. Representative morphologies and characterizations of the geometry of the molten pool for (a) NP cases and (b) WP cases, and the representative keyhole shape molten pool for (c) NP cases and (d) WP cases.

SEM images of typical melting-track cross-sections for the NP and WP cases are shown in

Fig.2a and Fig.2b, respectively. The MP has the shape of a semi-ellipse below the substrate for the NP cases and that of a semi-ellipse below the substrate surface with a reversed semi-ellipse 
above the surface for the WP cases. For better characterization of the MP geometry, two types of measurement were made for different cases, manually using the Image J software. For the NP cases, the width $(W)$ and the depth $(D)$, as well as the area $(A)$ of the MP were measured as shown in Figs. 2a and 2c. In addition to these characteristic parameters of the MP, an extra parameter named lower part depth $\left(D_{\text {low }}\right)$ was measured for the tracks made with powder layer, as shown in Figs. $2 \mathrm{~b}$ and $2 \mathrm{~d}$. The lower part depth is a critical parameter for the connection between subsequent layers during the deposition of the material in SLM processing. For each characterized track the MP dimensions were measured at least at four random positions along the track, in order to determine the variations of the MP shape along a track.

Furthermore, another shape of the MP was also observed for several tracks performed at higher powers and lower scan velocities of the laser for both the NP and WP cases. This shape, referred to as the keyhole shape by Dowden and Schulz (2017), is shown in Fig.2c and Fig.2d, respectively. Keyhole melting takes place at higher laser power, when the metal surface reaches the boiling temperature and the liquid on the surface starts to evaporate. A characteristic indentation appears in the melt, as shown in Fig.2c and Fig.2d, due to the vapor recoil pressure, as explained by Gladush and Smurov (2011). The keyhole MP geometry was characterized using the same method as for the ellipse shaped MP, in both the NP and WP cases. It should be mentioned that pores were commonly observed with the keyhole effect. Keyhole mode laser melting is not desired in such an application. Therefore, the keyhole shape MP was excluded in most of the following correlations and discussions, which are limited to defect-free solidified structures. 


\section{Results and discussion}

\subsection{Molten pool characterization of tracks without powder layer}

\subsubsection{Effect of laser parameters}

Fig.3 shows the dependence of the width and the depth of the MP on the laser power for different scan velocities, $V$, and energy densities, $E p$, for tracks without powder and with the original surface finish. Note that the velocity range in the experiments had to be adapted to the laser power (Table 1) and the trends shown in Fig. 3 are for the lowest and the highest velocity that were used at all power levels, i.e., 50 and $200 \mathrm{~mm} / \mathrm{s}$. Similarly, the lowest $E p$ and a higher one applied at all power levels, i.e., 14 and $28 \mathrm{~J} / \mathrm{mm}^{2}$, were selected to examine the variation of MP size with power at constant Ep. Note that the analysis is limited to ellipse-shaped MPs. The highest $E p$ was avoided in order to exclude MP with keyhole effect. The error bar shown in Fig. 3 for each data point is the standard deviation of the four measurements that were made for each data point at random positions along the melting track, in order to represent the variation of the MP size. Firstly, the results show that the variations of the MP size are negligible for most of the tracks, indicating a stable MP formation during the SLM process in the parameter range of this map, due to a stable state of heat and mass transfer in and around the MP. An exception with a much larger deviation is the case NP_O_P250V200. This is attributed to the keyhole effect by Dowden and Schulz (2017), which is usually not in a stable state during the MP formation. Secondly, for constant $V$, both $W$ and $D$ of the MP increase with increasing $P$, which is directly related to the increasing amount of the heat input with the increasing $P$, as shown in Fig.3a and Fig.3b. The MP also increases with increasing power even at constant $E p$, as shown in Fig.3c and Fig.3d. Specifically, the least-squares fitted linear correlations between the $W$ and $D$ of the MP and the $P$ for both constant $V$ and $E p$ are shown in Fig. 3 and given in form of equations in Table 2. It should be mentioned here that only the parameters in the range shown in the graphs of Fig. 3 were considered in these fitted correlations. Therefore, these 
correlations do not give a zero MP size when $P / E p$ goes to 0 . Also they are not applicable to molten pools that deviate from the semi-ellipse shape, such as the keyhole shape MP, for example. As shown in Fig. 3 and Table 2, both $W$ and $D$ increase with increasing $P$, due to the increasing heat input. The increase rates are higher for higher $E p$ or lower $V$. Additionally, the $W$ of the MP increases faster than $D$, both for constant $V$ and $E p$, as shown by the larger slope of the linear relationships. This is mostly attributed to convection, such as Marangoni flow in the liquid pool, as reported by Tsotridis et al. (1989).
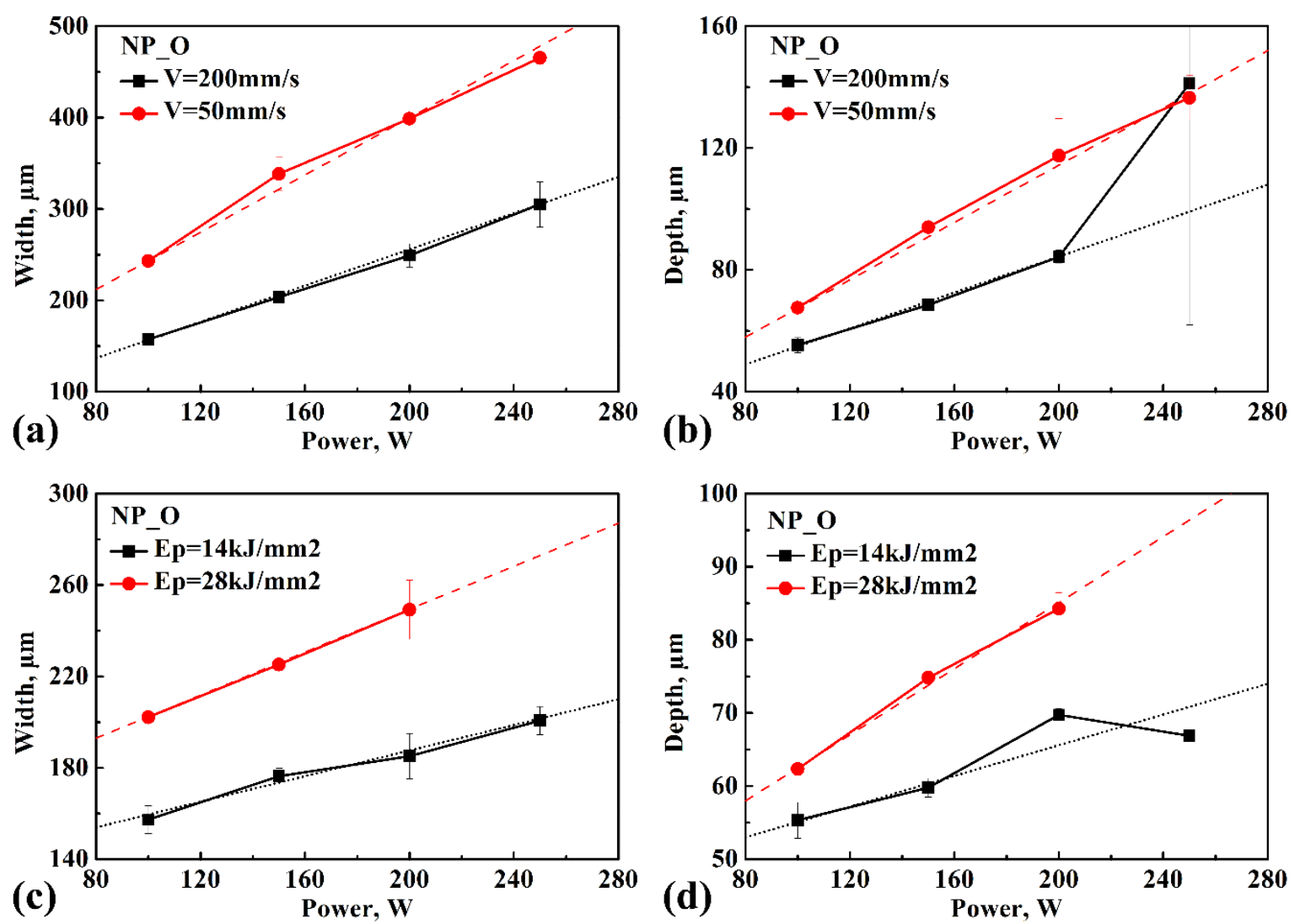

Fig.3. Variability of the $(\mathrm{a}, \mathrm{c})$ width and $(\mathrm{b}, \mathrm{d})$ depth of the MP with increasing power $P$ under $(\mathrm{a}, \mathrm{b})$ constant scan velocity, $V$ or $(\mathrm{c}, \mathrm{d})$ energy density, $E p$ for cases without powder and with the original plate surface (NP_O). 
Table 2. Variability of the MP width/depth with increasing laser power $P$ under constant laser scan velocity $\left(V, \mathrm{~mm} / \mathrm{s}^{2}\right)$ or constant energy density $\left(E p, \mathrm{~kJ} / \mathrm{mm}^{2}\right)$ for cases without powder and with the original plate surface (NP_O).

\begin{tabular}{|c|c|c|c|}
\hline $\begin{array}{c}\text { Constant } \\
\text { laser parameter }\end{array}$ & Power $P, \mathrm{~W}$ & Width $W, \mu \mathrm{m}$ & Depth $D, \mu \mathrm{m}$ \\
\hline$V=50 \mathrm{~mm} / \mathrm{s}$ & & $W=1.57 P+87$ & $D=0.47 P+20$ \\
\hline$V=200 \mathrm{~mm} / \mathrm{s}$ & & $W=0.99 P+58$ & $D=0.30 P+25$ \\
\hline$E p=14 \mathrm{~kJ} / \mathrm{mm}^{2}$ & $100-250$ & $W=0.28 P+132$ & $D=0.11 P+45$ \\
\hline$E p=28 \mathrm{~kJ} / \mathrm{mm}^{2}$ & & $W=0.47 P+155$ & $D=0.23 P+40$ \\
\hline
\end{tabular}

\subsubsection{Effect of surface sand blasting}

Fig.4 shows the surface microstructures of the substrate plates with $\mathrm{O}$ and SB surface conditions, imaged by SEM and EBSD. To describe the grain misorientation features and the sub-grain boundaries, a color EBSD map and a band contrast map were used for the plate with original surface finish and sand-blasted surface, respectively, as shown in Fig.4c and Fig.4d. As shown in Fig.4a, the surface for the $\mathrm{O}$ surface condition was flat and smooth, and Fig.4c shows that the grain structure was entirely equiaxed and the average grain size was around 40 $\mu \mathrm{m}$. A surface layer of finer grains with the thickness of around $35 \mu \mathrm{m}$ was also observed. Compared to the $\mathrm{O}$ surface condition, Fig. $4 \mathrm{~b}$ shows that a rough surface was obtained by the surface sand blasting. The surface layer of fine grains was removed only partly. A new surface structure with finer grains featuring many sub-grain boundaries, defined by grain boundary angles smaller than $2^{\circ}$, was formed, as shown in Fig. $4 \mathrm{~d}$. This indicates that the main difference between the $\mathrm{O}$ and SB surface conditions is the surface texture. In this work, the surface texture was evaluated in a simple way, by the length of the top surface edge of the solidified MP, visible in the cross-section. The edge length ratio of the $\mathrm{SB}$ surface to the $\mathrm{O}$ surface, $L_{\mathrm{SB}} / L_{\mathrm{O}}$, was around 
1.22. Furthermore, compared to the finer grain surface layer observed in the original plate, with a thickness of about $35 \mu \mathrm{m}$, an around $50 \mu \mathrm{m}$ thick surface layer with much finer grains or subgrains was observed in the plate with the SB.
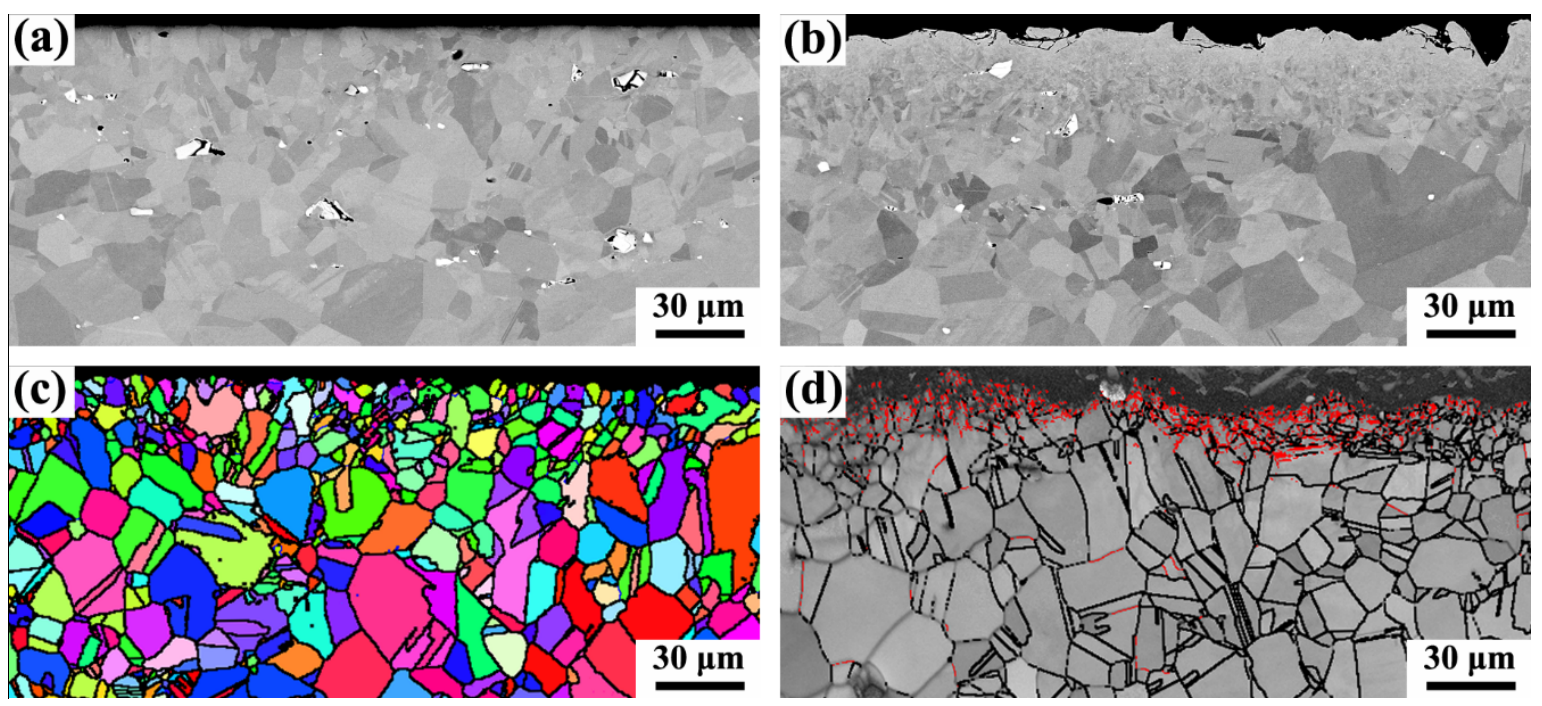

Fig.4. SEM micrographs (a, b) and EBSD patterns (c, d) of the substrate plate surface under different surface conditions: (a, c) original surface finish $(\mathrm{O})$; $(b, d)$ sand-blasted surface $(\mathrm{SB})$. (c) is a color EBSD map to show the random misorientations of the grains and (d) is a band contrast map with regular grain boundaries (GBs, black lines) and sub-GBs (red lines).

Fig.5a shows the dependence of the MP area on the Ep for NP cases with different surface conditions. The cross-section area of the samples with the sand blasted (SB) surface is systematically much larger than the area with the original $(\mathrm{O})$ surface finish processed with identical parameters. Most tracks show a stable MP with only weak deviations of the MP area. Larger MP area deviations are observed for cases O_P200, SB_P150, and SB_P200 and could be attributed to an unstable MP formation due to the keyhole effect. Then, for constant $P$, the MP area for both O and SB surface conditions increases with increasing Ep. Simplified linear correlations between the MP area and the Ep for different conditions are deduced from Fig.5a, in which the solid and dashed lines refer to the NP_O and the NP_SB cases, respectively. The linear correlations are given in Table 3. It can be seen in Fig.5a and Table 3, that the dependence 
of the MP area on $E p$ is not universal and is larger at higher $P$, as represented by the steeper slopes. Moreover, for each constant $P$, the MP area increases faster with the SB surface condition than with the $\mathrm{O}$ surface condition.
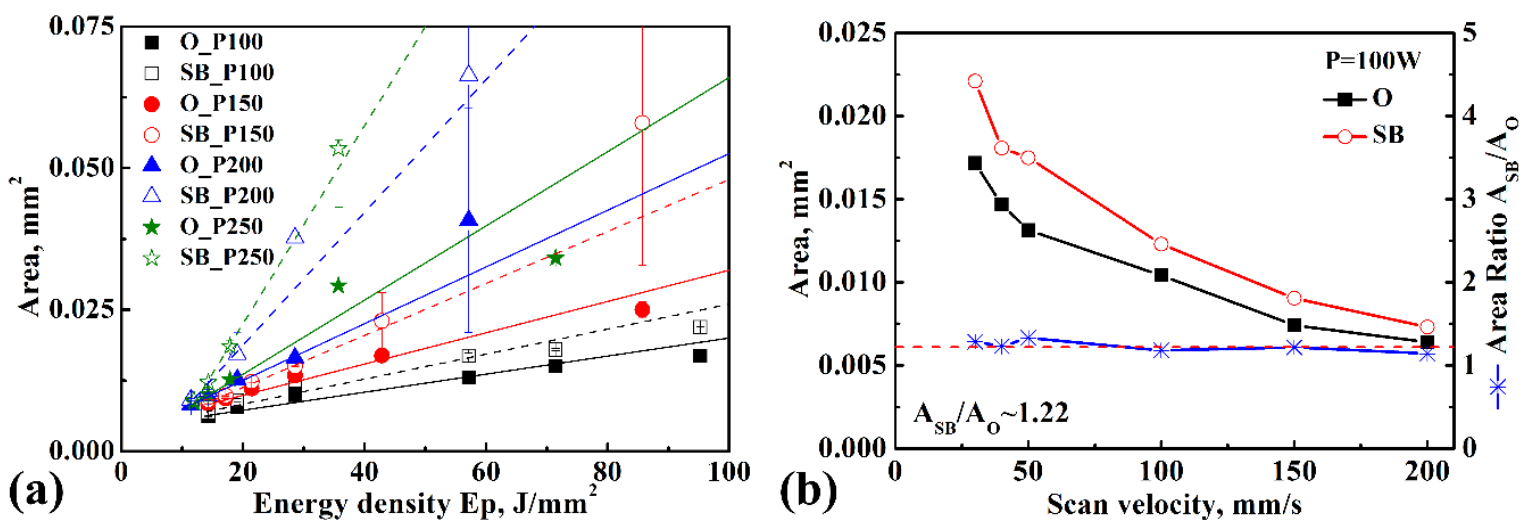

Fig.5. (a) Variability of the MP area with the increase of the energy density for NP cases with different surfaces, and (b) the area difference between O and SB surfaces for NP_P100 cases. The solid and dashed lines in Fig.5a refer to the NP_O and the NP_SB cases, respectively.

Table 3. Dependence of the MP area on the energy density for cases with no powder (NP).

$\begin{array}{ccc} & \text { MP area, } A, 10^{-6} \mathrm{~mm}^{2} & \text { MP area, } A, 10^{-6} \mathrm{~mm}^{2} \\ \text { Power, W } & \text { Original surface } & \text { Sandblasted surface }\end{array}$

\begin{tabular}{ccc}
\hline 100 & $A=159 E p\left[\mathrm{~J} / \mathrm{mm}^{2}\right]+4070$ & $A=221 E p\left[\mathrm{~J} / \mathrm{mm}^{2}\right]+3907$ \\
150 & $A=276 E p\left[\mathrm{~J} / \mathrm{mm}^{2}\right]+4353$ & $A=459 E p\left[\mathrm{~J} / \mathrm{mm}^{2}\right]+2118$ \\
200 & $A=501 E p\left[\mathrm{~J} / \mathrm{mm}^{2}\right]+2486$ & $A=1171 E p\left[\mathrm{~J} / \mathrm{mm}^{2}\right]-4657$ \\
250 & $A=655 E p\left[\mathrm{~J} / \mathrm{mm}^{2}\right]+489$ & $A=1749 E p\left[\mathrm{~J} / \mathrm{mm}^{2}\right]-12466$ \\
\hline
\end{tabular}

It has been well established in prior studies that the MP size increases with increasing energy density, Ep. Especially, the correlations between the MP size, including the $W, D$, and area, and the $E p$ were expressed by different types of fitting curves, as mentioned by Kusuma et al. (2017) 
and Ding et al. (2019), for example. However, in our work the correlations can be simply fitted with linear relations, as shown in Fig.5a and Table 3, if the cases with strong keyhole effect are excluded. It needs to be noted that the keyhole is not a stable state during the MP formation and should be considered carefully or avoided due to the presence of porosities, as will be discussed later in Section 3.3.

Fig. $5 \mathrm{~b}$ shows the dependence of the MP area on the scan velocity for the two surface finishes at $P=100 \mathrm{~W}$. The MP area decreases with increasing $V$, corresponding to a decreasing energy density, for both $\mathrm{SB}$ and $\mathrm{O}$ cases. The MP area ratio of the $\mathrm{SB}$ cases to the $\mathrm{O}$ cases, $A_{\mathrm{SB}} / A_{\mathrm{O}}$, remains constant at around 1.2 and is thus independent of the scan velocity. The increase of the MP area can be explained by an improved absorption of laser light by the textured SB surface and thus an enhanced heat input. Fig.6a and Fig. $6 \mathrm{~b}$ respectively show the schematic graphs of the $\mathrm{O}$ surface and the SB surface and the laser reflection on them, assuming geometrical optics. For the O smooth surface, there is normally one type of laser reflection, as shown in Fig.6a, for a surface positioned at the beam waist. On the other hand, there are normally three types of reflection surface after SB: (1) flat surface, (2) surface in deep cavity, (3) surface of the shallow pit. The absorption of laser energy is enhanced by the (2) deep cavity with smaller opening due to the trapping of the laser light inside the cavity and by the (3) shallow pit due to the increased surface area. As shown in Fig.4, compared to the main flat surface of the O surface, the major part of the SB surface was composed of (1) flat surface and (3) shallow pit. Therefore, the MP areas of the SB cases were larger than in the $\mathrm{O}$ cases. 


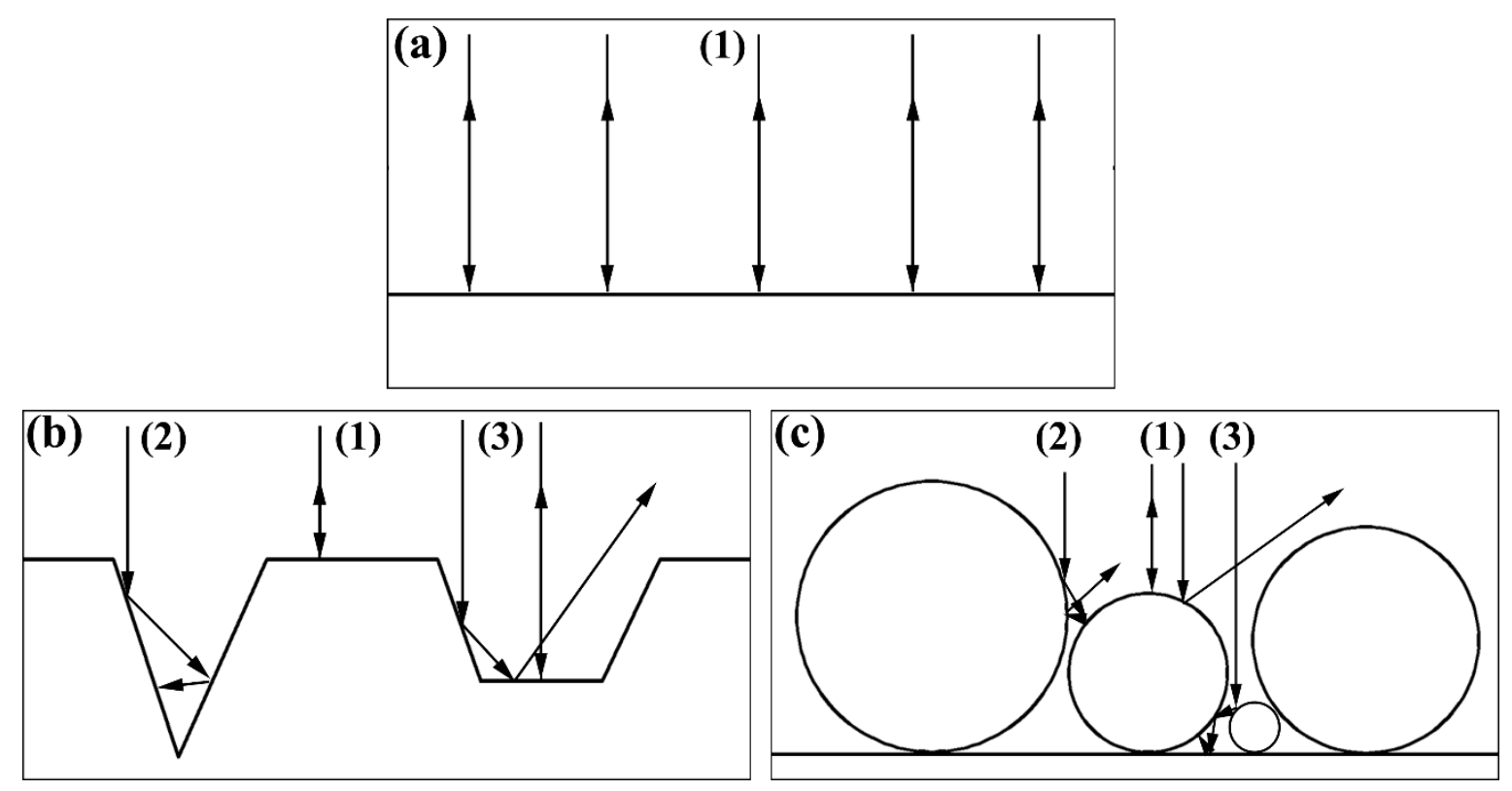

Fig.6. Schematic graphs of the laser reflection of different surface conditions: (a) Original smooth surface, O cases, (b) Sand blasted surface, SB cases, (c) surface with powder layer, WP cases.

\subsection{MP characterization with a powder layer}

\subsubsection{Effect of the presence of a powder layer}

Fig.7 shows the variability of the MP area with the increase of the energy density with different surface finishes. As shown in Fig.7, the deviation of the MP size was larger for most of the tracks compared to tracks without powder, shown in Fig.5a. It indicates an unstable MP formation on the surface with a powder layer during the SLM process. Furthermore, unlike for the surfaces without powder, shown in Fig.5a, for the cases with a powder layer no significant influence of the finish of the base surface (original or sandblasted) could be observed, neither on the MP shape and size nor on the microstructure. This indicates that the SB surface has no impact on the MP formation if there is a powder layer on the substrate surface. This is attributed to different reflection features with the surface powder layer by Boley et al. (2015). Fig.6c shows a schematic of the laser reflection on a substrate surface with one powder layer. There are three types of laser reflection in the powder layer surface: (1) direct reflection on the top surface of the particles, (2) multi-reflection between different particles, (3) multi-reflection or 
laser trapping inside the powder layer. The absorbability of the laser energy is supposed to be enhanced due to multiplied reflection events. Due to non-uniform particle size, as well as due to non-uniform particle distribution over the substrate surface, the reflection of the laser and the absorption of the energy on the surface should be non-uniform, which correspondingly results in an unstable MP formation in a single laser track. In addition, due to the blocking effect of the powder layer, most of the laser reflection and energy absorption occurs in the powder layer and only little laser light can reach the substrate surface. Therefore, the enhancement of laser absorption by the SB surface is eliminated.

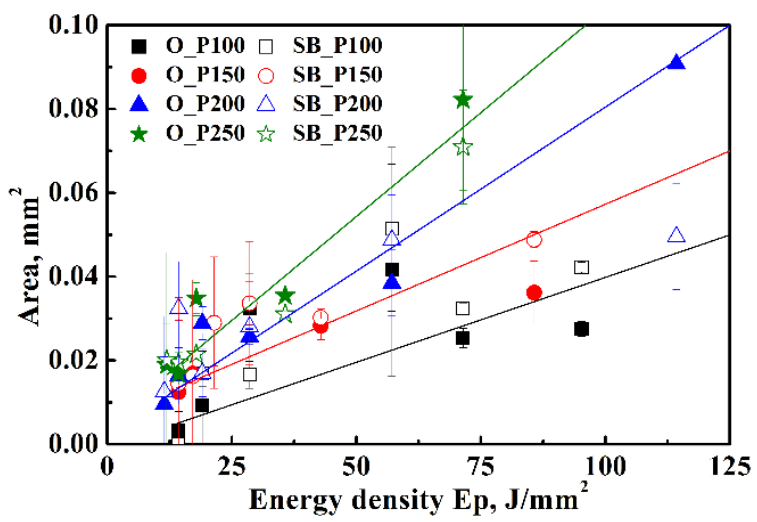

Fig.7. Dependence of the MP area on the energy density for WP cases with different surfaces.

Table 4. Dependence of the MP area on the energy density for cases with powder (WP).

\begin{tabular}{cc}
\hline Power, W & MP Area $A, 10^{-6} \mathrm{~mm}^{2}$ \\
\hline 100 & $A=405 E p\left[\mathrm{~J} / \mathrm{mm}^{2}\right]-676$ \\
150 & $A=509 E p\left[\mathrm{~J} / \mathrm{mm}^{2}\right]-6374$ \\
200 & $A=871 E p\left[\mathrm{~J} / \mathrm{mm}^{2}\right]-8816$ \\
250 & $A=991 E p\left[\mathrm{~J} / \mathrm{mm}^{2}\right]+4807$ \\
\hline
\end{tabular}


The correlations obtained in this and in preceding sections fit the experiment very well in the range of the parameters that are suitable for SLM processing (i.e., defect-free). Although they do not precisely fit all the data in the quite large range of processing parameters that was examined, they are helpful to estimate the suitability of the parameters and the size of the MP for additive manufacturing. Especially, the linear correlations can help to estimate the shape and dimensions of the molten pool easily, rather than by complex MP formation simulations.

\subsubsection{Characterization of the lower part of the MP}

The geometry of the lower part of the MP corresponds to either of the two types shown in Figs. $2 \mathrm{~b}$ and $\mathrm{d}$. The only exception are a few cases with low energy density (high scan velocity and low power), where the substrate was not remolten at all; they are further discussed in Section 3.3. Fig. 8 shows the variability of the depth of the lower part of the MP, $D_{\text {low }}$, with the laser scan velocity for different surfaces with powder layer. During the AM process, this parameter is important since it corresponds to the part of the underlying layer that is remelted. Similar to the size of the entire MP, the distinct deviations of $\underline{D}_{\text {low }}$ were observed for almost all tracks, with no general relationship between the two surface finishes. As mentioned in Section 3.2.1, most of the laser reflection and energy absorption occurs in the powder layer and only few light ray traces can reach the substrate surface. For most of the cases shown in Fig.8, the formation of the lower part of the MP below the substrate can be mainly attributed to the heat transfer from the remelted liquid above, rather than to direct absorption of the laser. Correspondingly, the dependence of the MP lower part depth, $D_{\text {low }}$, on the scan velocity of the laser followed the same trends as the variation of entire MP. Finally, for constant $P, D_{\text {low }}$ decreases linearly with increasing $V$ for most of the tracks in the high $V$ range. For the cases at slow $V$, especially at high power $(P \geq 200)$, the much faster increase of $D_{\text {low }}$ is attributed to the keyhole effect, which penetrates into the substrate and generates a deeper and unstable MP, as well as a much larger 
$D_{\text {low. }}$ The transition between the semi-ellipse and the keyhole shape of the lower part of the MP were marked in Figs. 8c and d. Additionally, it should be noted that for certain $P$, several tracks without melting of the substrate $\left(D_{\text {low }}=0 \mu \mathrm{m}\right)$ were observed when $V$ is too high, as shown in Fig.8a, $\mathrm{c}$ and $\mathrm{d}$, which indicates that the substrate was not remelted in those cases. Thus, the suitability of these parameters for the SLM process should be cautiously analyzed, and will be discussed in Section 3.3.
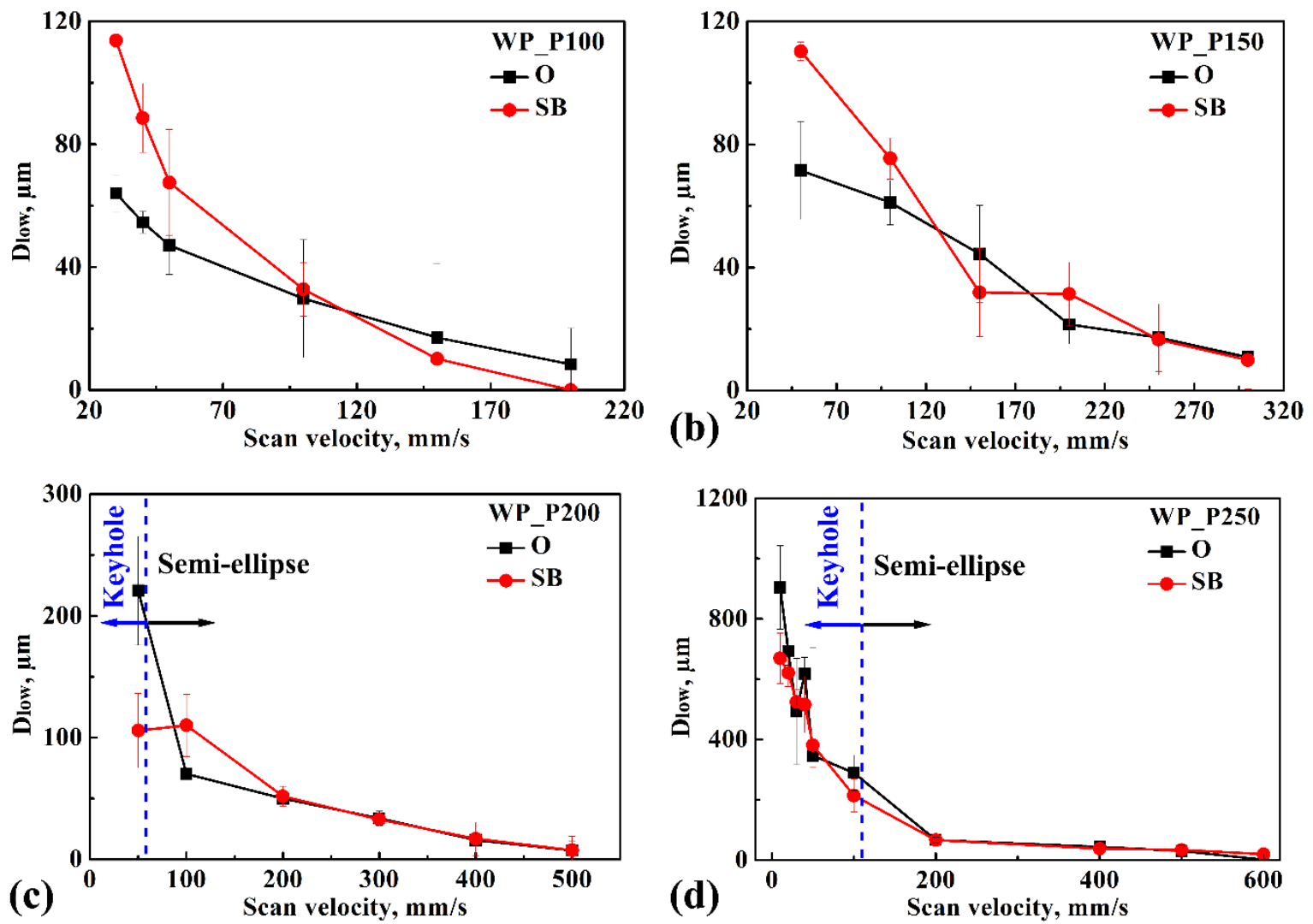

Fig.8. Dependence of the depth of the lower part of the MP, $D_{\text {low }}$, on the laser scan velocity with different surface finishes (O and SB) for (a) $P=100 \mathrm{~W}$, (b) $P=150 \mathrm{~W}$, (c) $P=200 \mathrm{~W}$ and (d) $P=250 \mathrm{~W}$.

Fig.9a shows the area ratio of the MP with and without powder layer $A_{W P} / A_{N P}$, with $O$ surface. The $A_{\mathrm{WP}} / \mathrm{A}_{\mathrm{NP}}$ shows no clear correlation with $P$ or $E p$, however, most of the values are close to the average value of 2 , which thus gives a reliable estimate of the order of magnitude. This indicates that a twice larger MP is formed in a single track with a powder layer compared to 
without powder layer, due to the enhancement of the energy absorption by the powder layer surface. Fig. $9 \mathrm{~b}$ shows the ratio of the lower part depth of the MP with a powder layer to the MP depth without powder and with $\mathrm{O}$ surface, $D_{\mathrm{low}}^{\mathrm{WP}} / D^{\mathrm{NP}}$. For each constant $P$, the ratio $D_{\mathrm{low}}^{\mathrm{WP}} / D^{\mathrm{NP}}$ first increases with increasing $E p$. The larger the $P$ applied, the higher is the rate of increase of the $D_{\mathrm{low}}^{\mathrm{WP}} / D^{\mathrm{NP}}$. For $P=100$ and $150 \mathrm{~W}$ the ratio stabilizes at a value of 0.75 . For the cases $P=200 \mathrm{~W}$ and $250 \mathrm{~W}$, the further increase of the depth ratio with larger $E p$ is attributed to the keyhole effect, which generates the instability of the MP size and consequently the instability of the $D_{\text {low }}^{\mathrm{WP}} / D^{\mathrm{NP}}$.
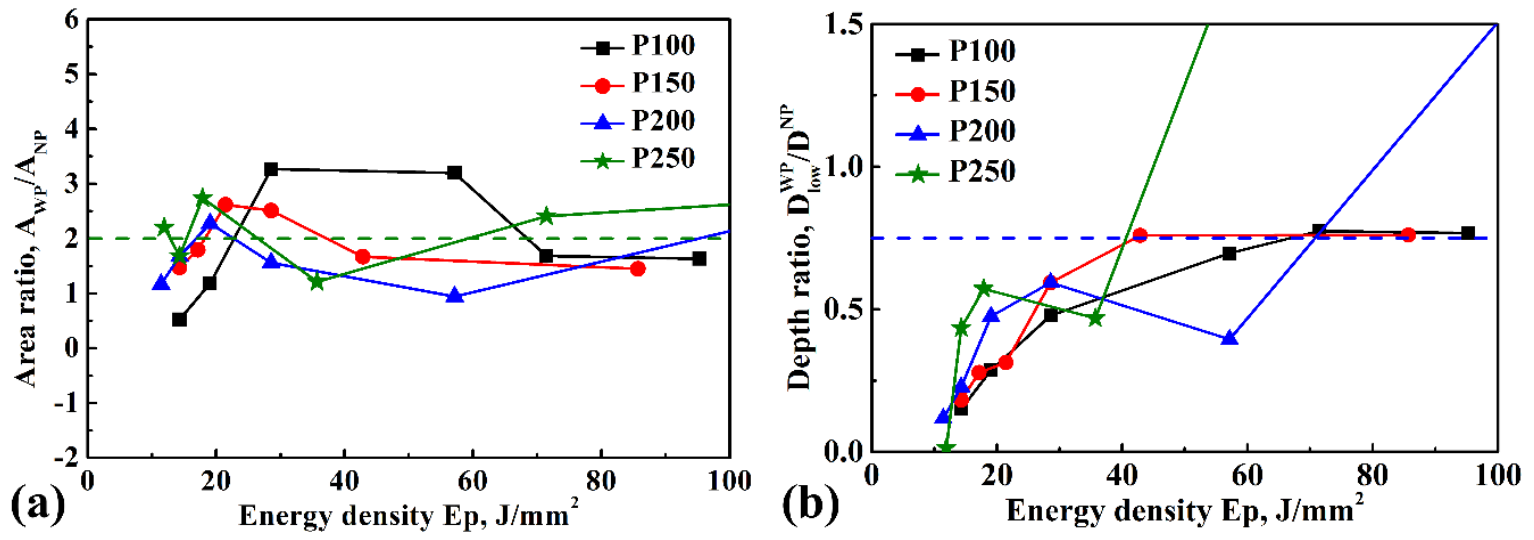

Fig.9. Ratio of (a) the area of the entire MP and (b) the lower part depth of the MP between WP cases and NP cases with O surface.

\subsection{Processing map}

Fig.10a shows the processing map that summarizes the observations of the MP structure with a powder layer. The applicable parameters for the SLM are represented by the center region in Fig.10a, with the boundaries drawn by the critical applicable parameter thresholds. Outside of this processing window three typical defects are observed: unstable MP formation, insufficient remelting of the substrate, and the keyhole effect combined with porosities in the MP. The MP is considered to be unstable if the standard deviation of the MP area is larger than one fifth of the average value of the MP area. Insufficient remelting of the substrate is considered if the 
depth of the lower part of the MP, $D_{\text {low }}$, is smaller than $10 \mu \mathrm{m}$. Finally, the porosity in the keyhole shaped MP is considered as a defect when its diameter is larger than $20 \mu \mathrm{m}$. The morphologies of representative unstable MP are shown in Fig.10b, corresponding to conditions WP_O_P100_V50 (b1 and b2) and WP_O_P100_V150 (b3 and b4), respectively. For two different positions of the same track, the shape, entire area, and the depth of the lower part of the MP are definitely different. This was observed for the WP_P100 and WP_P250 conditions, indicating that unstable MP formation is generated under either too low or too high laser power. For the cases with low $P$, an unstable MP was mainly attributed to a low amount of absorbed energy and low penetration of the heat input. For the cases with high $P$, Gladush and Smurov (2011) attributed the unstable MP mainly to the more vigorous melt motion and high evaporation pressure during the process, which results in both uneven MP and splashing of the melt and particles. The MP morphology for a case of insufficient remelting of the substrate is shown in Fig.10c, which mainly occurred in the higher scan-velocity region. Although the area of the entire MP was quite large for these cases, the remelting of the substrate was negligible, with the lower part depth of the MP close to $10 \mu \mathrm{m}$ or even smaller, corresponding to the cases with much higher $V$, mentioned in Section 3.2.2 and shown in Fig.8. In addition, some porosities and cracks could also be detected in the interface region of the MP and the substrate, as shown in Fig.10c, indicated by the red arrows. These defects can result in property deterioration due to the insufficient adhesion between different layers. Fig.10d shows the morphology of the MP with the keyhole effect, accompanied with porosities in the MP, which were normally observed at the bottom of the MP, as pointed out by the blue arrow. The keyhole effect and the porosities occurred when high laser power and low scan velocity were applied, which also means a large input energy density. Keyhole melting generally results from the boiling and vaporization of the material. The evaporation of the material also commonly occurs inside the MP due to a too large amount of energy input, i.e., under too high power or too slow scan velocity of the laser. 
In this case the metal vapor can be entrapped inside the MP and then generate porosities, especially at the bottom of the MP, as shown in Fig.10d. Higher laser power, even with the same input energy density, Ep, favors the keyhole effect as mentioned by Gladush and Smurov (2011).
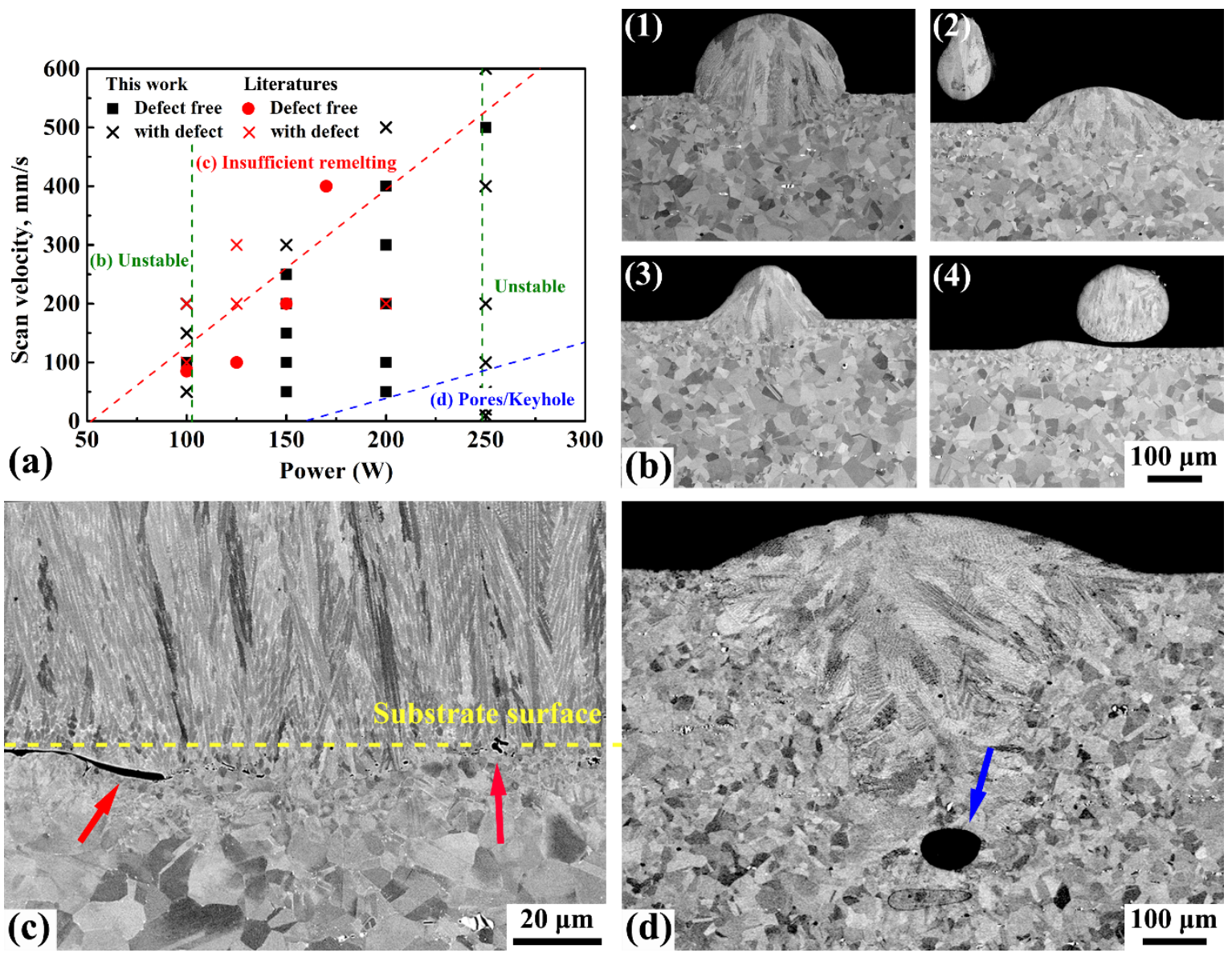

Fig.10. (a) Processing map compiled from the characterization of the WP cases and from literature data from Sadowski et al. (2016), Chlebus et al. (2015), Shi et al. (2016), and Wang et al. (2012). (b, c, d) Examples of the defects in the corresponding non-applicable regions: (b) unstable MP with b1 and b2 showing WP_O_P100_V50, and b3 and b4 showing WP_O_P100_V150, (c) insufficient remelting of the substrate, WP_SB_P150_V300, (d) keyhole effect with porosities, WP_O_P250_V40.

In addition to our single-track experiments, the processing map shown in Fig.10a also includes data from multilayer SLM processing of entire IN718 superalloy parts, available in literature. The results from literature are for workpieces or cube samples, from the work of Sadowski et al. (2016), Chlebus et al. (2015), Shi et al. (2016), and Wang et al. (2012). The parameters 
leading to a defect-free structure and to the presence of defects are marked by a magenta star and cross, respectively, as shown in Fig.10a. When comparing our results and the results from literature, it can be seen that most of the data points from literature fit the processing map very well. For instance, microcracks were observed for $P=125 \mathrm{~W}$ and $V=300 \mathrm{~mm} / \mathrm{s}$ by Shi et al. (Shi et al., 2016). However, there are two outlier data points: a defect located in the applicable parameter region $(P=200 \mathrm{~W}, V=200 \mathrm{~mm} / \mathrm{s})$ and a defect-free point in the insufficient remelting region $(P=170 \mathrm{~W}, V=400 \mathrm{~mm} / \mathrm{s})$. The pore/keyhole defect was observed in the case $P=200 \mathrm{~W}$ and $V=200 \mathrm{~mm} / \mathrm{s}$ as mentioned by Sadowski et al. (2016). This might be ascribed to the fact that the size of the laser spot used by Sadowski et al. was almost twice larger than in our work, which increases the total heat input during the SLM processing. Wang et al. (2012) obtained a defect-free sample in the case $P=170 \mathrm{~W}$ and $V=400 \mathrm{~mm} / \mathrm{s}$. However, it should be noted that in their work the powder layer thickness was only $20 \mu \mathrm{m}$ and also a much larger laser spot size of $100 \mu \mathrm{m}$ was used, which largely facilitates sufficient remelting of the substrate.

\section{Conclusion}

By characterizing the molten pool (MP) geometry of a large number of single-track experiments of IN718 under different conditions and parameters, the effects of the laser parameters, surface conditions and powder layer on the MP formation, and their interactions during the selective laser melting (SLM) process were systematically investigated.

Linear correlations between the size of the MP and the laser parameters were deduced. The area ratio of the MP with and without powder layer was estimated to be of the order of 2 . The depth ratio of the MP lower part of the cases with and without powder layer increased with the laser power and finally was stable at around 0.75 for high power and in absence of keyhole effects. The correlations obtained in this work can be used to estimate the size of the MP for additive 
manufacturing conditions. The linear correlations can help to easily estimate the shape and dimensions of the molten pool.

Without powder layer, the surface sand blasting was observed to increase the MP area, due to laser light trapping by the deep cavities and the increased surface area. With a powder layer, most of the laser reflections and energy absorption occur within the powder layer. Due to the blocking of the powder layer, the enhanced absorption of the laser energy on the SB surface is not present.

A processing map of the SLM parameters was compiled, with one region marked as the applicable parameter region, and three inapplicable parameter regions, where insufficient melting, unstable MP, or porosities/keyhole effect can occur. The processing map also fits well most of the data from literature obtained from for realistic multilayer SLM processing. This indicates that the processing map obtained from our work can be applied to estimate the applicability of parameter combinations for SLM on IN718 and potentially other nickel-base superalloys. However, improvements and additional experiments are still needed to provide a more accurate and general map. First, the effect of multilayer processing should be included in order to have a more realistic representation of the heat transfer in SLM processing. Further, the effect of additional parameters, particularly the laser spot size, the powder particle size, and the thickness of the the powder deposition layer should be investigated.

\section{Acknowledgement}

This research was funded by the Institut de Recherche Technologique "Matériaux Métallurgie Procédés" (IRT M2P) and by the French National research Agency (ANR) via the project RESEM 2018. We also acknowledge support from the French State through the program

" Investment in the future" operated by the National Research Agency (ANR) and referenced by ANR-11 LABX-0008-01 (LabEx DAMAS). 
Yuze Li et al., Effect of ...on the molten pool formation in SLM, J. Mater. Process. Technol. 289 (2021), 116930

\section{References}

Acharya, R., Sharon, J.A., Staroselsky, A., 2017. Prediction of microstructure in laser powder bed fusion process. Acta Materialia 124, 360-371. https://doi.org/10.1016/j.actamat.2016.11.018

Amato, K.N., Gaytan, S.M., Murr, L.E., Martinez, E., Shindo, P.W., Hernandez, J., Collins, S., Medina, F., 2012. Microstructures and mechanical behavior of Inconel 718 fabricated by selective laser melting. Acta Materialia 60, 2229-2239. https://doi.org/10.1016/j.actamat.2011.12.032

Bandyopadhyay, A., Traxel, K.D., 2018. Invited review article: Metal-additive manufacturing-Modeling strategies for application-optimized designs. Additive Manufacturing 22, 758-774. https://doi.org/10.1016/j.addma.2018.06.024

Boley, C.D., Khairallah, S.A., Rubenchik, A.M., 2015. Calculation of laser absorption by metal powders in additive manufacturing. Appl. Opt., AO 54, 2477-2482. https://doi.org/10.1364/AO.54.002477

Chen, H., Chen, Y., Liu, Y., Wei, Q., Shi, Y., Yan, W., 2020. Packing quality of powder layer during counterrolling-type powder spreading process in additive manufacturing. International Journal of Machine Tools and Manufacture 153, 103553. https://doi.org/10.1016/j.ijmachtools.2020.103553

Chen, Q., Guillemot, G., Gandin, C.-A., Bellet, M., 2018. Numerical modelling of the impact of energy distribution and Marangoni surface tension on track shape in selective laser melting of ceramic material. Additive Manufacturing 21, 713-723. https://doi.org/10.1016/j.addma.2018.03.003

Chlebus, E., Gruber, K., Kuźnicka, B., Kurzac, J., Kurzynowski, T., 2015. Effect of heat treatment on the microstructure and mechanical properties of Inconel 718 processed by selective laser melting. Materials Science and Engineering: A 639, 647-655. https://doi.org/10.1016/j.msea.2015.05.035

Dilip, J.J.S., Zhang, S., Teng, C., Zeng, K., Robinson, C., Pal, D., Stucker, B., 2017. Influence of processing parameters on the evolution of melt pool, porosity, and microstructures in Ti-6Al-4V alloy parts fabricated by selective laser melting, Prog. Addit. Manuf. 2, 157-167. https://doi.org/10.1007/s40964017-0030-2

Ding, X., Koizumi, Y., Wei, D., Chiba, A., 2019. Effect of process parameters on melt pool geometry and microstructure development for electron beam melting of IN718: A systematic single bead analysis study. Additive Manufacturing 26, 215-226. https://doi.org/10.1016/j.addma.2018.12.018

Dowden, J., Schulz, W. (Eds.), 2017. The Theory of Laser Materials Processing: Heat and Mass Transfer in Modern Technology, 2nd ed, Springer Series in Materials Science. Springer International Publishing.

Fabbro, R., 2010. Melt pool and keyhole behaviour analysis for deep penetration laser welding. J. Phys. D: Appl. Phys. 43, 445501. https://doi.org/10.1088/0022-3727/43/44/445501

Fotovvati, B., Wayne, S.F., Lewis, G., Asadi, E., 2018. A Review on Melt-Pool Characteristics in Laser Welding of Metals. Advances in Materials Science and Engineering 2018. https://doi.org/10.1155/2018/4920718

Ghosh, S., Ma, L., Levine, L.E., Ricker, R.E., Stoudt, M.R., Heigel, J.C., Guyer, J.E., 2018. Single-Track MeltPool Measurements and Microstructures in Inconel 625. JOM 70, 1011-1016. https://doi.org/10.1007/s11837-018-2771-x

Gladush, G.G., Smurov, I., 2011. Physics of Laser Materials Processing: Theory and Experiment, Springer Series in Materials Science. Springer-Verlag, Berlin Heidelberg. 
Yuze Li et al., Effect of ...on the molten pool formation in SLM, J. Mater. Process. Technol. 289 (2021), 116930

Gokuldoss, P.K., Kolla, S., Eckert, J., 2017. Additive Manufacturing Processes: Selective Laser Melting, Electron Beam Melting and Binder Jetting-Selection Guidelines. Materials 10, 672. https://doi.org/10.3390/ma10060672

Heeling, T., Cloots, M., Wegener, K., 2017. Melt pool simulation for the evaluation of process parameters in selective laser melting. Additive Manufacturing 14, 116-125. https://doi.org/10.1016/j.addma.2017.02.003

Kenel, C., Grolimund, D., Li, X., Panepucci, E., Samson, V.A., Sanchez, D.F., Marone, F., Leinenbach, C., 2017. In situ investigation of phase transformations in Ti-6Al-4V under additive manufacturing conditions combining laser melting and high-speed micro-X-ray diffraction. Scientific Reports 7, 16358. https://doi.org/10.1038/s41598-017-16760-0

Khairallah, S.A., Anderson, A.T., Rubenchik, A., King, W.E., 2016. Laser powder-bed fusion additive manufacturing: Physics of complex melt flow and formation mechanisms of pores, spatter, and denudation zones. Acta Materialia 108, 36-45. https://doi.org/10.1016/j.actamat.2016.02.014

Kumar, S., 2014. 10.05 - Selective Laser Sintering/Melting, in: Hashmi, S., Batalha, G.F., Van Tyne, C.J., Yilbas, B. (Eds.), Comprehensive Materials Processing. Elsevier, Oxford, pp. 93-134. https://doi.org/10.1016/B978-0-08-096532-1.01003-7

Kumar, P., Farah, J., Akram, J., Teng, C., Ginn, J., Misra, M., 2019. Influence of laser processing parameters on porosity in Inconel 718 during additive manufacturing. Int. J. Adv. Manuf. Technol. 103, 1497-1507. https://doi.org/10.1007/s00170-019-03655-9

Kusuma, C., 2016. The Effect of Laser Power and Scan Speed on Melt Pool Characteristics of Pure Titanium and Ti-6Al-4V Alloy for Selective Laser Melting. Wright State University.

Kusuma, C., Ahmed, S.H., Mian, A., Srinivasan, R., 2017. Effect of Laser Power and Scan Speed on Melt Pool Characteristics of Commercially Pure Titanium (CP-Ti). J. of Materi Eng and Perform 26, 3560-3568. https://doi.org/10.1007/s11665-017-2768-6

Li, S., Xiao, H., Liu, K., Xiao, W., Li, Y., Han, X., Mazumder, J., Song, L., 2017. Melt-pool motion, temperature variation and dendritic morphology of Inconel 718 during pulsed- and continuous-wave laser additive manufacturing: A comparative study. Materials \& Design 119, 351-360. https://doi.org/10.1016/j.matdes.2017.01.065

Liverani, E., Toschi, S., Ceschini, L., Fortunato, A., 2017. Effect of selective laser melting (SLM) process parameters on microstructure and mechanical properties of 316L austenitic stainless steel. Journal of Materials Processing Technology 249, 255-263. https://doi.org/10.1016/j.jmatprotec.2017.05.042

Moges, T., Ameta, G., Witherell, P., 2019. A Review of Model Inaccuracy and Parameter Uncertainty in Laser Powder Bed Fusion Models and Simulations. J. Manuf. Sci. Eng 141, 040801-040801-14. https://doi.org/10.1115/1.4042789

Murr, L.E., Martinez, E., Pan, X.M., Gaytan, S.M., Castro, J.A., Terrazas, C.A., Medina, F., Wicker, R.B., Abbott, D.H., 2013. Microstructures of Rene 142 nickel-based superalloy fabricated by electron beam melting. Acta Materialia 61, 4289-4296. https://doi.org/10.1016/j.actamat.2013.04.002

Qiu, C., Panwisawas, C., Ward, M., Basoalto, H.C., Brooks, J.W., Attallah, M.M., 2015. On the role of melt flow into the surface structure and porosity development during selective laser melting. Acta Materialia 96, 72-79. https://doi.org/10.1016/j.actamat.2015.06.004 
Yuze Li et al., Effect of ...on the molten pool formation in SLM, J. Mater. Process. Technol. 289 (2021), 116930

Sadowski, M., Ladani, L., Brindley, W., Romano, J., 2016. Optimizing quality of additively manufactured Inconel 718 using powder bed laser melting process. Additive Manufacturing 11, 60-70. https://doi.org/10.1016/j.addma.2016.03.006

Saedi, S., Shayesteh Moghaddam, N., Amerinatanzi, A., Elahinia, M., Karaca, H.E., 2018. On the effects of selective laser melting process parameters on microstructure and thermomechanical response of Ni-rich NiTi. Acta Materialia 144, 552-560. https://doi.org/10.1016/j.actamat.2017.10.072

Scime, L., Beuth, J., 2019. Melt pool geometry and morphology variability for the Inconel 718 alloy in a laser powder bed fusion additive manufacturing process. Additive Manufacturing 29, 100830. https://doi.org/10.1016/j.addma.2019.100830

Shi, Q., Gu, D., Xia, M., Cao, S., Rong, T., 2016. Effects of laser processing parameters on thermal behavior and melting/solidification mechanism during selective laser melting of TiC/Inconel 718 composites. Optics \& Laser Technology 84, 9-22. https://doi.org/10.1016/j.optlastec.2016.04.009

Tsotridis, G., Rother, H., Hondros, E.D., 1989. Marangoni flow and the shapes of laser-melted pools. Naturwissenschaften 76, 216-218. https://doi.org/10.1007/BF00627691

Wang, Z., Guan, K., Gao, M., Li, X., Chen, X., Zeng, X., 2012. The microstructure and mechanical properties of deposited-IN718 by selective laser melting. Journal of Alloys and Compounds 513, 518-523. https://doi.org/10.1016/j.jallcom.2011.10.107

Zhang, T., Li, H., Liu, S., Shen, S., Xie, H., Shi, W., Zhang, G., Shen, B., Chen, L., Xiao, B., Wei, M., 2018. Evolution of molten pool during selective laser melting of Ti-6Al-4V. J. Phys. D: Appl. Phys. 52, 055302. https://doi.org/10.1088/1361-6463/aaee04 